\title{
Toxoplasmose em animais domésticos e silvestres de Manaus-Amazonas (1)
}

\author{
José João Ferraroni ( ${ }^{2}$ ) \\ Mauro Célio de Almeida Marzochi (ग)
}

\begin{abstract}
Resumo
Através da reação de hemaglutinação indireta para toxoplasmose, foram examinadas amostras de sangue de dez diferentes espécies de animais domésticos e silvestres, e de dois grupamentos humanos, um em Manaus e outro em Roraima. Em 108 animais domésticos $29(90,6 \%)$ dos gatos (Felis catus) foi positivo para o teste, assim como $13(68,4 \%)$ dos cães (Canis familiaris); $15(60 \%)$ dos bois (Bos sp); $7(41,2 \%)$ das galinhas (Gallus sp) e $6(40 \%)$ dos patos (Cairina sp). Dos 104 animais silvestres examinados $3(75 \%)$ das onças (Felis $\mathrm{sp}) ; 31(63,2 \%)$ dos primatas (Saimiri $\mathrm{sp})$ e $11(61,1 \%)$ dos roedores (Proechimys sp) foram reagentes. A incidência de positividade nas populações humanas foram $70,6 \%$ e $64,9 \%$ em Manaus e Roraima, respectivamente.
\end{abstract}

\section{INTRODUÇÃo}

Numerosas espécies de animais, incluindo o homem, têm sido encontradas naturalmente infectadas pelo Toxoplasma gondii (Nicolle \& Manceaux, 1908). A freqüência dessas infecções, contudo, pode variar de uma área para outra.

$\mathrm{Na}$ cadeia epidemiológica da toxoplasmose, apenas o gato e alguns felídeos silvestres são considerados hospedeiros definitivos, por eliminarem pelas fezes, as formas de resistência oocistos, disseminando-os pelo meio ambiente (Hutchinson, 1965; Frenkel et al., 1970). Alguns artrópodes, como moscas e baratas, podem atuar como agentes mecânicos na disseminação desses oocistos. Os hospedeiros intermediários, por outro lado, albergam cistos e pseudocistos em seus tecidos, podendo infectar outros animais quando ingeridos pelo carnivorismo e pela infecção intra uterina, mais rara, porém de grande importância médica.
Os testes sorológicos para toxoplasmose, quando aplicados em adultos de uma população evidenciam, de regra geral, a proporção de portadores de anticorpos anti-toxoplasma correspondente, na maioria dos casos, a infecçôes adquiridas no passado. Segundo Camargo et al. (1976) neles estão presentes anticorpos do tipo IgG em níveis baixos, estando ausentes os do tipo $\lg \mathrm{M}$, o que pode ser evidenciado pelas reações de Hemaglutinação Indireta (RHAI) ou de Imunofluorescência, consideradas equivalentes apresentando títulos muito próximos entre si e năo ultrapassando em positividade a diluições de 1:4.000.

Infecções em gestantes podem causar danos ao feto, especialmente no primeiro trimestre da gravidez. Podem também ocasionar mortes em outros animais e em particular nos cães os quais são altamente susceptiveis à toxoplasmose, sendo freqüentemente confundida com hidrofobia e cinomose (Grzywinsk \& Bochdalek, 1966).

Apesar da alta prevalência de toxoplasmo. se encontrada no Estado do Amazonas (Ribeiro et al., 1977), existem poucos trabalhos realizados neste sentido, existindo grande necessidade de intensificar esses estudos, o que tem sido enfatizado reiteradamente pela WHO (WHO/FAO, 1968 e WHO, 1969).

Este trabalho relata a prevalência da infecção pelo $T$. gondii em diferentes espécies de animais, domésticos e silvestres, capturados na periferia da cidade de Manaus. A taxa de infecção em populações humanas de Manaus é também comparada àquelas da tribo Sanomä vivendo em uma área iso!ada no Território de Roraima.

(1) $\rightarrow$ Pesquisa n: 2017/102 do INPA realizada com auxilio financeiro do Conselho Nacional de Desenvolvimento Científico e Tecnológico - CNPq.

(2) - Instituto Nacional de Pesquisas da Amazônia, Manaus.

(3) - Escola Nacional de Saúde Pública/Fundação Oswaldo Cruz, Rio de Janeiro, pesquisador visitante do INPA, Manaus. 


\section{MATERIAIS E MÉTODOS}

O presente estudo foi desenvolvido na cidade de Manaus, Estado do Amazonas e no Território de Roraima. A regiāo de Manaus é caracterizada pelo clima equatorial, quente e úmido e está situada a 40 metros em relação ao nivel do mar. $\mathrm{Na}$ área periurbana, compreendida pelo bairro do Aleixo e adjacências. na cidade de Manaus, foram capturados 108 animais domésticos constituidos por 32 gatos, 25 bois, 19 cães, 17 galinhas, 15 patos e 104 animais silvestres sendo 49 macacos, 33 gambás, 18 ratos selvagens e 4 onças, eram representados em sua maioria, por animais adultos, de ambos os sexos.

Amostras de sangue de todos os animais foram retiradas por venóclise ou punção cardiaca, imediatamente após a captura. O sangue coletado foi deixado por um período de 3 horas em temperatura ambiente para a retração do coágulo. O soro obtido era centrifugado e guardado a baixa temperatura $\left(-20^{\circ} \mathrm{C}\right)$ até a realização dos testes.

$\mathrm{Na}$ mesma área foram escolhidas ao caso, amostras de sangue de 51 indivíduos adultos, de ambos os sexos, aparentemente sadios, ali residentes ou que freqüentavam a localidade por período mínimo de 8 horas diárias.

No Território de Roraima, na regiäo de Uauaris, situado a $\left(40^{\circ} \mathrm{N} 08^{\prime} \mathrm{N}, 64^{\circ} \mathrm{W} 29^{\prime} \mathrm{W}\right)$, e a 900 metros em relação ao nivel do mar, a grande distância de Manaus (ver mapa), foram obtidas amostras de sangue de 37 silvícolas adultos, de ambos os sexos, pertencentes à tribo Sanomã.

Utilizou-se a reação de Hemaglutinação indireta (RHAI), conforme padronização de Jacobs \& Lunde (1957), com reagentes oriundos da Eiken Chemical Co, Ltda. - Katsushita, Tokyo - Japäo. Antes de ser adsorvido por hemácias de carneiro o soro era inativado a $56^{\circ} \mathrm{C}$ por 30 minutos. A diluição inicial foi de $1: 4$ e o teste foi considerado positivo a partir da diluição do soro a 1:16.

TABELA I - Prevalência de reaçōes positivas para Toxoplasmose (RHAI) em sôros humanos e de animais domésticos e silvestres, em Manaus - Amazonas

\begin{tabular}{|c|c|c|c|c|c|c|c|}
\hline \multirow{2}{*}{ ES PE I ES } & \multirow{2}{*}{$\begin{array}{l}\text { No Exa- } \\
\text { minados }\end{array}$} & \multicolumn{6}{|c|}{ SOROLOGIA POSITIVA (RHAI - título $\geqslant 1: 16$ ) } \\
\hline & & Masc. & $\%$ & Fem. & $\%$ & Total & $\%$ \\
\hline HUMANOS Habitantes da área & 51 & 22 & 43,14 & 14 & 27,45 & 36 & 70,59 \\
\hline Indígenas de Roraima & 37 & 15 & 40,54 & 09 & 24,32 & 24 & 64,86 \\
\hline $\begin{array}{l}\text { FELLIDEOS } \\
\text { DOMESTICOS (Felis catus) }\end{array}$ & 32 & 15 & 46,88 & 14 & 43,75 & 29 & 90,63 \\
\hline CANIDEOS (Canis familiaris) & 19 & 08 & 42,11 & 05 & 26,32 & 13 & 68,43 \\
\hline BOVINOS (Bos sp) & 25 & 09 & 36,00 & 06 & 24,00 & 15 & 60,00 \\
\hline GALINACEOS (Gallus sp) $\left({ }^{\bullet}\right.$ ) & 17 & - & - & 一 & - & 07 & 41,18 \\
\hline PALMIPEDES (Cairina $\mathbf{s p})\left({ }^{\bullet}\right)$ & 15 & - & - & - & - & 06 & 40,00 \\
\hline $\begin{array}{l}\text { FELIDEOS } \\
\text { SILVESTRE (Felis sp) }\end{array}$ & 04 & 02 & 50,00 & 01 & 25,00 & 03 & 75,00 \\
\hline $\begin{array}{ll}\text { MARSUPIAIS } & \begin{array}{l}\text { (Didelphis marsupialis) } \\
\text { (Marmosa sp) }\end{array}\end{array}$ & 33 & 12 & 36,36 & 09 & 27.28 & 21 & 63,64 \\
\hline PRIMATAS (Saimiri sp) & 49 & 18 & 36,74 & 13 & 26,53 & 31 & 63,27 \\
\hline ROEDORES (Proechimys) & 18 & 08 & 44,44 & 03 & 16,67 & 11 & 61,11 \\
\hline
\end{tabular}

(•) Nб̆o foram separados por sexo. 


\section{REsultados}

Dos 51 soros testados, de indivíduos que residiam ou freqüentavam a área de Manaus (Bairro do Aleixo), em $70,6 \%$ evidenciou-se anticorpos para toxoplasma e dos 37 soros de indígenas da tribo Sanomã em Roraima, 64,9\% foram positivos.

Entre os mamíferos domésticos os percentuais de positividade ao teste, variaram de $90,6 \%$ (gatos) a $60 \%$ (bois) e entre as aves de $41,2 \%$ (galinhas) a $40 \%$ (patos). Nos mamíferos silvestres os percentuais variaram de $75 \%$ (onças) a $61,1 \%$ (roedores). Dos animais estudados as mais baixas prevalências se verificaram entre as aves (tabela I e figura I).

De uma maneira geral houve concordância de nossos resultados com os outros autores, mas o índice de infecção pelo $T$. gondii na maioria dos animais estudados foi relativamente mais alto do que aqueles encontrados nos estudos anteriores (tabela II).
Observou-se nos dois grupos humanos, assim como em todas as espécies de animais estudadas, um predomínio de reações soroló. gicas positivas no sexo masculino (figura I).

\section{Discussão}

Usando a reação de Imunofluorescência (RIFI) Ribeiro et al., (1977) encontrou 75,8\% de soros reagentes para $T$. gondii nos 1.024 indivíduos examinados em 11 municípios do Estado do Amazonas. O resultado de $70,6 \%$ obtido no presente estudo usando a RHAl em indivíduos na cidade de Manaus, estâo bem próximos daqueles. Nossos resultados são similares àqueles citados por Deane et al. (1963), que encontrou $67 \%$ de positividade entre 354 amostras do Território do Amapá e com aqueles encontrados por Jamra (1964) em 300 indivíduos examinados no Estado de São Paulo onde $68 \%$ foram positivos.

Baruzzi (1970) também encontrou altos títulos $(51 \%)$ entre 254 índios vivendo em vilas

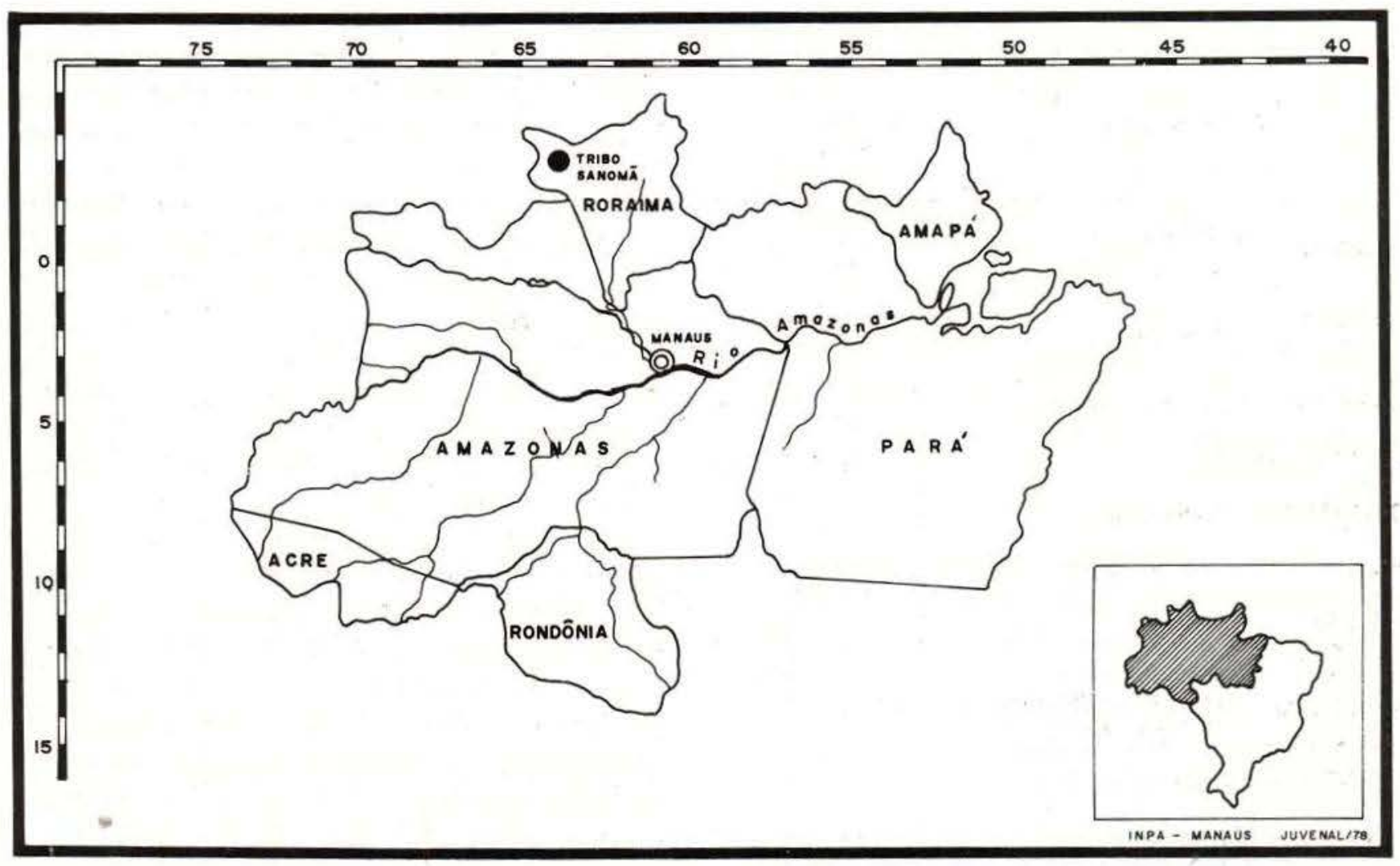

Mapa da localização geográfica da cidade de Manaus e da tribo Sanomã 
TABELA II - Taxas comparativas de infecçōes por T. gondil no homem e outros animais, neste e em outros estudos

\begin{tabular}{|c|c|c|c|c|c|c|c|c|c|}
\hline Humanos & $75.8^{1}$ & $70.6^{\circ}$ & $68.0^{3}$ & $67.0^{2}$ & $64.9^{\circ}$ & $51.0^{4}$ & $50.0^{5}$ & $14-34.0^{5}$ & $2.0^{5}$ \\
\hline Gatos & $95.0^{12}$ & $96.0^{\circ}$ & $86.0^{8}$ & $54.0^{9}$ & $58.0^{11}$ & $55.0^{7}$ & $50.9^{6}$ & $27.0^{10}$ & \\
\hline Cães & $90.0^{17}$ & $82.0^{12}$ & $79.2^{16}$ & $68.4^{\circ}$ & $57.1^{14}$ & $51.5^{13}$ & $25.0^{15}$ & & \\
\hline Macacos & $63.3^{\circ}$ & $60.0^{6}$ & $41.7^{6}$ & $28.7^{21}$ & $1.8^{20}$ & & & & \\
\hline Bois & $60.0^{\circ}$ & $60.0^{19}$ & $7.2^{18}$ & & & & & & \\
\hline Gambás & $100.0^{6}$ & $75.0^{12}$. & $63.6^{\circ}$ & & & & & & \\
\hline Roedores & $61.1^{*}$ & $25.0^{22}$ & & & & & & & \\
\hline Onças & $75.0^{\circ}$ & $66.6^{6}$ & & & & & & & \\
\hline Galinhas & $41.2^{\circ}$ & & & & & & & & \\
\hline Patos & $40.0^{\circ}$ & & & & & & & & \\
\hline
\end{tabular}

(*) Nossos achados

(1) Ribeiro et al (1977)

(2) Deane et al (1963)

(3) Jamra et al (1964)

(4) Baruzzi (1901)

(5) Wallace et al (1974)

(6) Sogorb et al (1972)

(7) Miller \& Feldman (1953)
(8) Gibson \& Eyles (1956)

(9) Jones et al (1957)

(10) Soave (1968)

(11) Berenco et ol (1969)

(12) Canese et al (1976)

(13) Giovonnoni (1958)

(14) Fernandes \& Barbosa (1972)

(15) Baruzi et ol (1971)
(16) Coutinho et al (1968)

(17) Sogorb et al (1976)

(18) Paine (1969)

(19) Kozojed et al (1976)

(20) Guimaräes \& Freken (1971)

(21) Chhabra et al (1976)

(22) Sogorb et al (1977) isoladas no Alto Xingu. Isto foi surpresa em virtude da ausência de animais domésticos no local, incluindo o gato que atua como hospedeiro definitivo. De fato Wallace et al. (1974), usando a reação de Sabin-Feldman (RSF) para toxoplasmose encontrou uma incidência muito baixa de infecção $(2 \%)$ em populações primitivas em Nova Guiné, as quais não tinham con. tato com animais domésticos ou gatos selvagens, enquanto que, em populações que mantinham contato com alguma forma de felídeos apresentavam altos títulos (14 a $34 \%$ ). Eles também encontraram $50 \%$ de reações positivas em populações que se alimentavam de gatos selvagens na Coiômbia.

A alta incidência de reações positivas entre os índios Sanomã, muito nos surpreendeu. uma vez que eles mantêm pouco contato com animais, raramente comem carne, sendo seu alimento principal, farinha de mandioca e fru tas silvestres. Não praticam o nomadismo $€$ poucas pessoas os visitam.

Toxoplăsmose é mais freqüente onde a umidade relativa do ar está entre 22 e $80 \%$ devido a maior permanência do cisto infectante no solo (Frenkel \& Dubey 1972) e entre as populações que vivem em climas quente e úmido (Feldman, 1974). Isto talvez seja responsável pela menor incidência de infecções entre os índios Sanomã, devido o clima da região ser mais frio que o de Manaus.

Nossos resultados sugere a existência de outra forma de disseminação além dos felídecs. Isto pode ser também o caso da taxa relativamente alta de infecção encontrada nos animais silvestres na periferia de Manaus (tabela I) onde o contato com fezes de felídeos é pouco provável. Nos carnívoros há a possibilidade da ingestão de animais contaminados, alternativamente uma certa percentagem de infecção intra uterina pode ocorrer, embora isso seja também considerado excepcional. A taxa de $63 \%$ nos macacos platirrinos (Saimiri sp) é de difícil explicação, uma vez que eles excepcionalmente descem das copas das árvores e só se alimentam de frutos e folhas. A participação de felídeos silvestres, na contaminação do meio ambiente, poderia explicar nossos achados, porém, sabe-se que na Amazônia é baixa a densidade e grande a dispersão desses animais. 


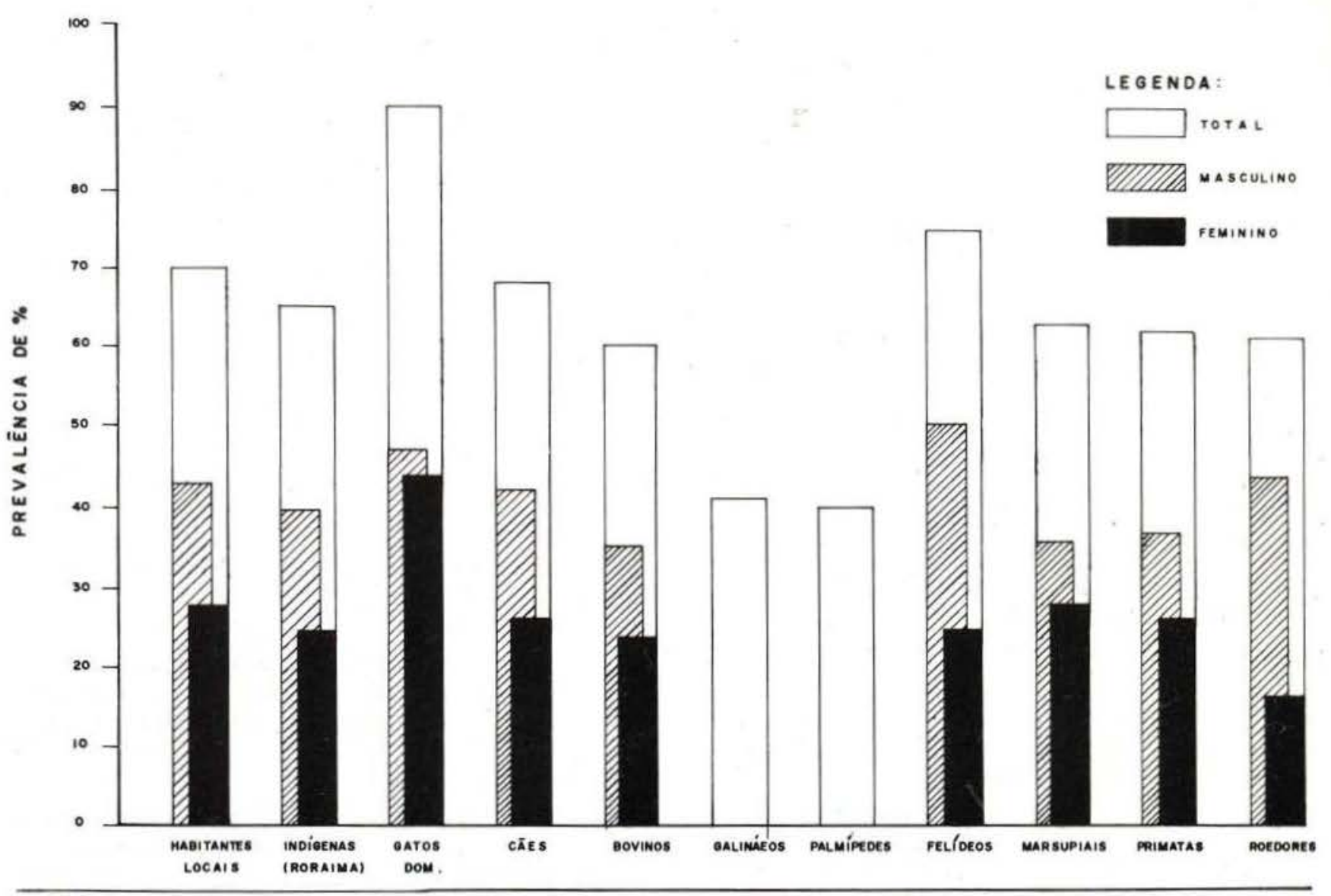

Figura 1 - Prevalência de reações positivas para o toxoplasmose em soros humanos e de animais domésticos e silvestres, segundo o sexo, em Manaus - AM.

Observou-se entre as populações humanas e em todas as espécies de animais examinadas, uma maior prevalência de anticorpos ao toxoplasma no sexo masculino, com exceçã̃o das aves, onde o sexo não foi considerado. Não encontramos explicação satisfatória para o fato, sem precedentes referidos na literatura consultada.

A toxoplasmose parece ser uma infecçāo muito comum entre humanos, animais domésticos e silvestres na região de Manaus. Porém, a ausência de gatos na aldeia indígena e a remota possibilidade de felídeos silvestres, devido a sua baixa densidade, grande dispersão e curto periodo de eliminação de oocistos, terem êxito na contaminaçăo do ambiente em grau suficiente, para explicar a alta prevalência nos silvícolas e primatas näo humanos, chama a atenção para a existência de mecanismos de transmissão ainda não esclarecidos. Carece, porém, de maiores estudos a referida zoonose na região Amazônica.

\section{Agradecimentos}

Os autores agradecem ao Prof. Dr. Mamo. ru Suzuki, da Universidade de Gunma - Japão por ter enviado o antígeno, a Mari Otsuka pela colaboração técnica e ao Francisco Moraes de Andrade pela colaboração na captura dos animais.

\section{SUMMARY}

Blood samples from ten different species of domestic and wild animals from two distinct areas were examined using an Indirect Hemagglutination test for toxoplasmosis. The human populations from the two areas, Manaus - Amazonas and indigenous Indians from the Territory of Roraima were also tested. 
In a sample of 108 domestic animals, $29(90.6 \%)$ of the cats (Felis catus) exmained were positive for the test, as were $13(68.4 \%)$ of the dogs (Canis familiaris); $15(60 \%)$ of the cattlee (Bos sp); $7(41.2 \%)$ of the chickens (Gallus sp) and $6(40 \%)$ of the ducks (Cairina $s p)$. Of the 104 wild animals examined $3(75 \%)$ of the wild cats (Felis sp): $31(63.2 \%)$ of the primates (Saimiri $\mathrm{sp}$ ) and $11(61.1 \%)$ of the rodentes (Proechimys $\mathrm{sp}$ ) were found to be reactive. The positive incidence in the human populations were $70.6 \%$ and $64.9 \%$ from Manaus and Roraima respectively.

The authors discuss the results in the light of the current knowledge of the epidemiology of toxoplasmosis. Emphasizing that trasmission mechanisms must exist for which there are, at present, no explanation.

\section{BIBLIOGRAFIA CITADA}

BARUZZI, R. G.

1970 - Contribution to the study of the toxoplasmosis epidemiology. Serologic survey among the indians of the Upper Xingú River, Central Brasil. Rev. Inst. Med. Trop. São Paulo, 12: 93-104.

Baruzzi, R.; Deane, M. P.; Kamayama, I.;

Penteado JR., H. \& Guimaräes, E. C.

1971 - Inquérito para toxoplasmose em animais do Alto Xingú (Brasil Central). Rev. Paul. Med. $77: 45$.

Berenco, A.; lalla, F.; Cavallini - Sampieri, L.;

Bechelli, G. \& Cavallini, F.

1969 - Prevalence of toxoplasmosis among domestic and wild animals in the area of Siena, Italy. Amer. J. Trop. Med. Hyg. 18: 391-394.

Camargo, M. E.; Leser, P. G. B. \& Leser, W. S. P.

1976 - Diagnostic information from serological tests in human toxoplasmosis. II - Evalutive study of antibodies and serological patterns in acquired toxoplasmosis, are detected by hemagglutinations, complement fixation, $\lg G$ - and $\lg M$ - immunoflorescence tests. Rev. Inst. Med. Trop. São Paulo. 18: 227-238.

Canese, A.; Canese, J.; Galeano, A. \& De Vargas, H.

1976 - Anticuerpos anti Toxoplasma gondil en 100 sueros de animales domésticos y selvaticos del Paraguay. Rev. Parag. Microb. 11: 13-14.

ChHabra, M. B.; Mahajan, R. C. Ganguly, N. K.

\& CHITKARA, N. L.

1976 - Prevalence of toxoplasma antibodies in rhesus monkeys in India. Trop. Geog. Med. 28 : 101-103.

Coutinho, S. G.; ANDrade, C. M.; Lopes, A. C.; ChIARINi, C. \& Ferreira, L. F,

1968 - Observaçōes sobre a presença de anticorpos para Toxoplasma gondii em cães de área suburbana do Rio de Janeiro. Rev. Bras. Med. Trop. 2 : 285-295.
DEANE, L, M, et alii.

1963 - Inquérito de toxoplasmose e tripanossomíase realizado no Território do Amapá pela III Bandeira Científica do Centro Acadêmico "Oswaldo Cruz" da F.M.U.S.P. Rev. Med. (São Paulo), $47: 1 \cdot 2$.

FELdMAN, H. A.

1974 - Toxoplasmosis : an over-view. Bull. N. Y. Acad. Med., 2: 110-127.

Fernandes, J. W. \& Barbosa, W.

1972 - Toxoplasmose - Notas sobre ocorrência em animais domésticos em Goiânia (1970). Rev. Pat. Trop., 2 : 259-265.

Frenkel, J. K. \& DUbey, J. P.

1972 - Toxoplasmosis and its prevention in cats and. man. Journ. Infect. Dis., 126 (6) : 664-673.

Frenkel, J, K.; Dubey, J. P. \& Miller, N. D.

1970 - Toxoplasma gondii in cats: fecal stages identified as coccidial oocist. Science $167: 893-896$.

Gibosn, C. L. \& Eyles, D. E.

1956 - Toxoplasma infections in animals associated with a case of human congenital toxoplasmosis. Amer. J. Trop. Med. Hyg., 6: 991-1000.

GIovannoni, M.

1958 - Consideraçōes gerais sobre toxoplasma e toxoplasmose - Isolamento do agente etiológico e pesquisa de anticorpos em cães. Tese. Esc. Sup. Agric, e Vet. Curitiba, Paraná.

GRZIWINSKI, L. \& BOCHDALEK, R.

1966 - Experimental toxoplasmosis in dogs. Acta Parasit. Pol., 14 : 77-89.

Hutchinson, W. M.

1965 - Experimental transmission of Toxoplasma gondii. Nature (London), 206: 961-962.

JACOBS, L. \& LUNDE, L.

1957 - A hemagglutination test for toxoplasmosis.' J. Parasit., 43 : 308-314.

JAMRA, L. M. F.

1964 - Contribuição para a epidemiologia de toxo. plasmose. Inquérito em 100 famílias de uma área da cidade de São Paulo. Tese. Faculdade de Medicina da Universidade de Săo Paulo.

Jones, F. C.; Eyles, D. E. \& Grison, C. L.

1957 - Prevalence of toxoplasmosis in the domestic cat. Amer. J. Trop. Med. Hyg., $6: 820-826$.

Kozojed, V., BLAZEK, K. \& Amin, A.

1976 - Incidence of toxoplasmosis in domestic animals in Afghanistan. Folia Parasit , 23. (3) : 273-275

MILler, L. T. \& Fedman, H. A.

1953 - Incidence of antibodies for toxoplasma among various animal species. J. Infect. Dis., 92 : 118-120. 
Nery-Guimarãs, F.; Franken, A. D. \& Chagas, W. A.

1971 - Toxoplasmose em primatas não humanos. II - tentativas de infecçōes experimentais em Macaca mullata, Cebus apella e Calittithix jacchus e pesquisa de anticorpos em várias espécies de platyrrhinus. Mem. Inst. Oswaldo Cruz, 96: 97-111.

Nicole, M. M. M. C. \& Mandeaux, L.

1901 - Sur un protozoaire nouveau du gondil (Toxoplasma n. sp.). Arch. Inst. Pasteur, Tunis, 2: 97 .

PAINE, G. D.

1969 - Toxoplasmosis in Lower mammals. J. Protozool., 16(2) : 371-372.

Ribeiro, E. B.; Ferraroni, J. J. \& Camargo, M. E.

1977 - Investigação sorológica da Prevalência de Toxoplasmose no Amazonas. In : XIII Congresso da Sociedade Brasileira de Medicina Tropical, II Congresso da Sociedade Brasileira de Parasitologia. Brasília -27 de fevereiro a 03 de março de 1977.
SOgorb, S. F.; JAMrA, L. F. \& GuTMARĨEs, E. C.

1976 - Toxoplasmose em cães de São Paulo. Rev. Inst. Med. Trop. São Paulo, 18 : 36-41.

1977 - Toxoplasmose em animais de Săo Paulo Brasil. Rev. Inst. Med. Trop. São Paulo, 19: 191-194.

SOGorb, S. F.; JAMra, L. F.; GUIMARÄEs, E. C. \& DEANE, M. P.

1972 - Toxoplasmose expontânea em animais domésticos e silvestres, em São Paulo. Rev. Inst. Med. Trop. Sắo Paulo, 14 : 314-320.

SOAVE, A. O.

1968 - Serological Survey for toxoplasma antibodies in a colony of research dogs and cats in $\mathrm{Ca}$. lifornia. Amer. J. Vet. Res., 29: 1505-1506.

Wallace, G. D.; Zigas, V. \& Gajdusk, D. C.

1974 - Toxoplasmosis and cats in New Guinea. Am. J. Trop. Med. Hyg., $23: 8-13$.

WHO/FAO EXPERT COMMITTEE ON ZOONOSIS

1968 - Second report, Geneve.

WORLD HEALTH ORGANIZATION

1969 - Toxoplasmosis. Tech Rep. Serv., 431.

(Aceito para publicação em $28 / 11 / 77$ ) 